\title{
Effect Of Pre-Tensioned Level on Axial Stress-Strain Behaviour of Confined Concrete: A Review
}

\author{
Chee-Loong Chin ${ }^{1 *}$, Chau-Khun $\mathrm{Ma}^{2}$, Jia-Yang Tan ${ }^{3}$, Abdullah Zawawi Awang ${ }^{4}$, Wahid Omar ${ }^{5}$ \\ ${ }^{I}$ Ph.D Candidate, Department of Structure and Materials, Faculty of Civil Engineering, Universiti Teknologi Malaysia, Malaysia \\ ${ }^{2}$ Senior Lecturer, Department of Structure and Materials, Faculty of Civil Engineering, Universiti Teknologi Malaysia, Malaysia \\ ${ }^{3}$ Ph.D Candidate, Department of Structure and Materials, Faculty of Civil Engineering, Universiti Teknologi Malaysia, Malaysia \\ ${ }^{4}$ Senior Lecturer, Department of Structure and Materials, Faculty of Civil Engineering, Universiti Teknologi Malaysia, Malaysia \\ ${ }^{5}$ Professor, Office of Chancellery, Universiti Teknologi Malaysia, Malaysia \\ *Corresponding author E-mail: clchin4@graduate.utm.my
}

\begin{abstract}
External passive confinement has been used as strengthening scheme to rehabilitate existing reinforced concrete buildings. Passive confinement requires a certain lateral dilation of concrete prior to the activation of the confining effect. Applying pre-tensioned force to the confining material can eliminate the needs of such lateral dilation. This paper presents a review on previous studies conducted about pretensioned level in confined concrete. A short discussion is done based on the effect of pre-tensioned level to the three regions of stressstrain curve. It was found that pre-tensioned level affects the stress-strain behaviour of confined concrete. Pre-tensioned level that is too high decreases the strain capacity of the confined concrete. This review suggests that there exists an optimum pre-tensioned level for each confining material.
\end{abstract}

Keywords: confined concrete; active confinement; pre-tensioned level; activation of confinement; stress-strain behaviour.

\section{Introduction}

Rehabilitation and retrofitting of existing reinforced concrete buildings are necessary for old buildings in order to ensure the safety of the buildings. The integrity and stability of the buildings are questionable when the service life of the buildings is exceeded or when the usage of the buildings have been changed. Problem arises when the load carrying capacity of the buildings, particularly columns, is less than the loads acting on the columns. Demolishing the building or replacing the column can be very costly and time consuming. A solution that can fit into these situations are strengthening the columns by external confinement.

Most common materials including concrete exhibit lateral dilation when they are subjected to axial compressive loads. The lateral dilation is due to Poisson effect as well as the formation of microcracks in concrete. Confining material restricts the lateral dilation as if a confining pressure is applied to the concrete. The confining material also acts to keep the concrete intact when concrete start to crack under compressive loads.

In recent years, confined concrete, particularly fiber reinforced polymer (FRP) confined concrete has received significant attention in research. As highlighted in a recent review [1], there have been a great number of research conducted experimentally and analytically on FRP-confined concrete. The confining pressure provided by the confining material can be quantified by using (1) based on the equilibrium condition of the confining material as shown in Fig. 1.

$$
f_{l}=\frac{2 E_{f} t_{f} \varepsilon_{f}}{D}
$$

where, $f_{l}$ is confining pressure; $E_{f}$ is elastic modulus of the confining material; $\underline{t}_{f}$ is thickness of the confining material; $\varepsilon_{f}$ is ultimate tensile strain of the confining material; and $D$ is diameter.

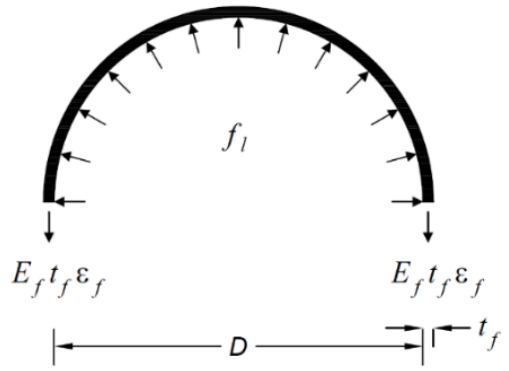

Fig. 1: Confining pressure of confinement (reproduced from: [1])

Nonetheless, previous studies showed that in FRP-confined concrete, the rupture strain of the FRP hoops is lower than the rupture strain of FRP in tensile test [2-5]. However, this has only been reported in FRP-confined concrete. A hoop strain reduction factor was introduced in order to properly quantify the confining pressure and the stress-strain behaviour of FRP-confined concrete. The confining pressure that takes into the hoop strain reduction factor is named as the actual confining pressure by Lam and Teng [6]. However, it was found that the confining effect of this type of confinement requires a certain lateral dilation of concrete in order to be activated as evidence from the stress-strain behaviour of confined concrete [7]. This shortcoming can be rectified by introducing a confining pressure prior to the dilation of concrete. This type of confinement is known as active confinement while confinement without such confining pressure is known as passive confinement. In recent years, research on active confinement has 
been increasing [7-25]. Hence, the understanding of pre-tensioned mechanisms becomes important. Actively confined concrete does not require lateral dilation of concrete in order to be activated; instead the pre-applied confining pressure activates the confinement from the beginning. Thus, this allows active confinement to fully utilize the confining material.

\section{Review on Pre-Tensioned Level}

Concrete is actively confined by applying pre-tensioned force to the confining material which exerts the confining pressure prior to the lateral dilation of concrete. The confining pressure induced from the pre-tensioned force can be quantified by using the equilibrium condition of the confining material as shown in Fig. 1. As the concrete dilates when subjected to axial compressive load, the confining pressure increases in accordance with the stress-strain behaviour of the confining material. When the confining material reaches the rupture strain, the confinement fails and the effect of the confinement subsides.

Since pre-tensioned force is introduced to the confining material, the confining material in actively confined concrete ruptures earlier compared to the same confining material in passively confined concrete. This has been proven experimentally from previous research [7, 14]. It was found that the amount of pre-tensioned level affects the stress-strain behaviour of confined concrete $[7,8$, 10, 12-14]. A comparison between confined concrete with and without pre-tensioned force is illustrated in Fig. 2.

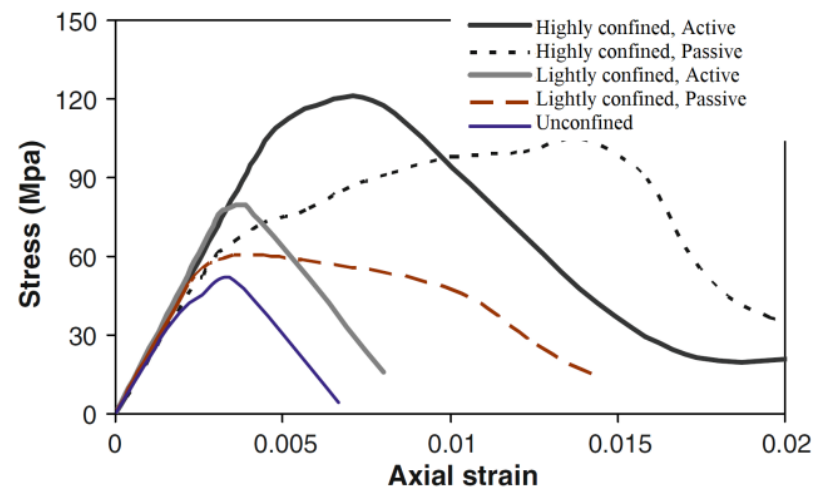

Fig. 2: Compressive behaviour of active and passive confined concrete (reproduced from: [7])

In this review, the findings from those research are summarized in Table 1 . The effect of pre-tensioned level is discussed separately in three regions in stress-strain curve of confined concrete. Additionally, pre-tensioned level is determined based on (2) and (3) to indicate the stress states of the confining materials.

Level of pre-tensioned stress $=\left(\left(f_{u l t}-f_{\text {pre }}\right) / f_{u l t}\right) \times 100 \%$

Level of pre-tensioned strain $=\left(\left(\varepsilon_{u l t}-\varepsilon_{p r e}\right) / \varepsilon_{u l t}\right) \times 100 \%$

where, $f_{u l t}$ is the peak stress of the confining material; $f_{\text {pre }}$ is the pre-tensioned stress; $\varepsilon_{u l t}$ is the rupture strain of the confining material; $\varepsilon_{\text {pre }}$ is the pre-tensioned strain of the confining material.

\subsection{Effect on Pre-Peak Region}

In [7], it was found both actively-confined concrete and passively confined concrete have similar initial slopes in stress-strain curve. This implies that the initial stiffness of confined concrete is not affected by pre-tensioned level. This was also reported in other research $[10,12,14]$.

In passively confined concrete, the pre-peak stress-strain curve shows that stiffness degradation occurs relatively earlier than actively-confined concrete. This can be seen in Fig. 2 where the elastic limit of passive confined concrete is relatively smaller than their active companions. This indicated that micro-cracks started earlier in passively-confined concrete and the presence pre- tensioned force delayed the formation of micro-cracks. Similar observations were reported in the experimental investigation conducted by Lee et al. [12]. In [26], it was believe that the magnitude of confining pressure decreases lateral strain by delaying the formation of micro-crack as illustrated in Fig. 3. Since the confining pressure increases when pre-tensioned level is increased, hence higher pre-tensioned level delays the formation of micro-cracks.

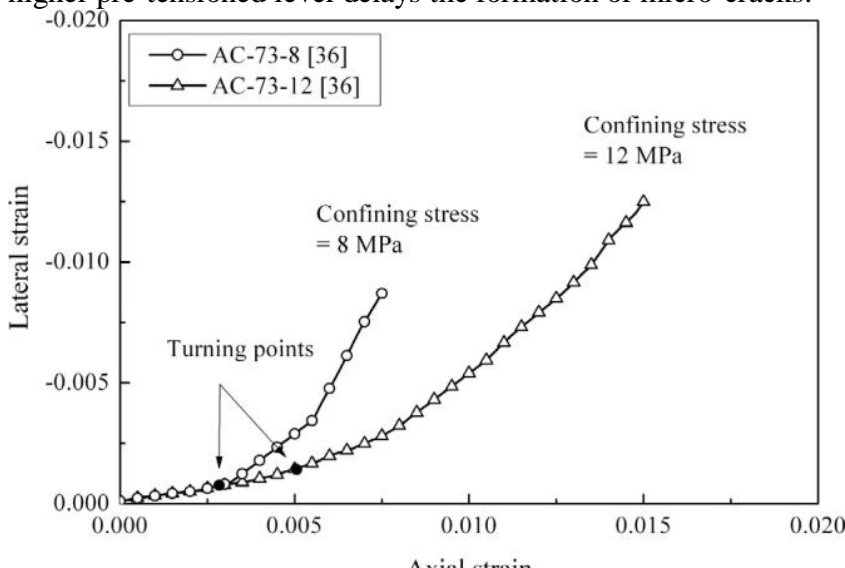

Fig. 3: Lateral-axial strain of actively confined concrete (retrieved from [26])

\subsection{Effect on Peak Point}

In [14], it was found that increasing the pre-tensioned level improved the peak stress and peak strain of confined concrete. However, increasing the pre-tensioned level too much resulted in reduction of both peak stress and peak strain as shown in Fig. 4. This is due to the fact that the overly pre-tensioned confinement ruptured before the confined concrete develops its strength as seen in the small lateral strain exhibits by the confined concrete upon failure. As in [7], increasing the pre-tensioned level improved the peak stress and peak strain of confined concrete. Early rupture of confinement was not reported because the pre-tensioned level was much lower. Similar observations were reported in other recent studies $[10,12]$.

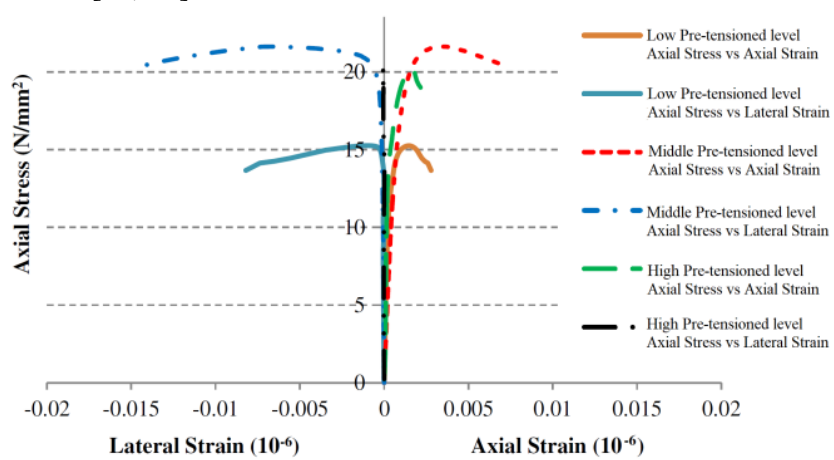

Fig. 4: Influence of pre-tensioned level on the compressive behaviour of confined concrete (reproduced from: [14])

The peak point of confined concrete has been researched extensively. The peak stress of the confined concrete have been expressed by modifying (4) developed by [27]. The confining pressure, $f_{l}$ is obtained by using (5) and the volumetric ratio, $\rho_{v}$ is obtained by using (6). 


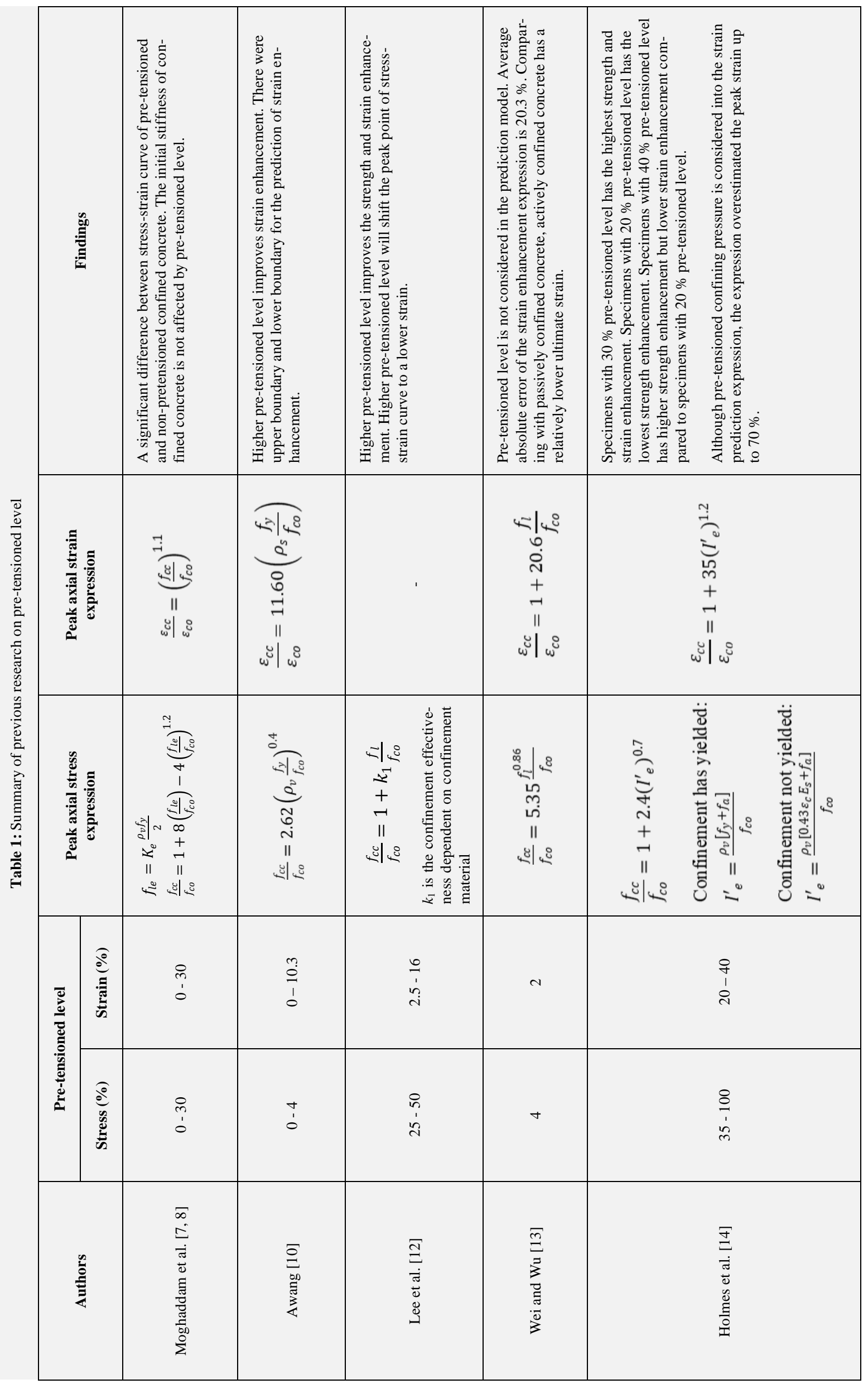




$$
\begin{aligned}
& \frac{f_{c c}}{f_{c o}}=1+k_{1} \frac{f_{l}}{f_{c o}} \\
& f_{l}=\rho_{v} \frac{f_{y}}{f_{c o}} \\
& \rho_{v}=\frac{\mathrm{V}_{s}}{\mathrm{~V}_{c}}
\end{aligned}
$$

where $f_{c c}$ is the peak axial stress of confined concrete; $f_{c o}$ is the peak axial stress of unconfined concrete; $k_{1}$ is confinement efficiency factor; $f_{y}$ is the yield stress of confining material; $\mathrm{V}_{s}$ is volume of confining material; and $\mathrm{V}_{c}$ is volume of concrete.

Expression for peak axial strain has been developed based on several variety of regression methods. However, some of the expressions developed by researchers did not consider the effect of pretensioned level $[8,10,12,13]$. This resulted in certain degree of inaccuracy of the expressions to predict the peak point of the confined concrete. Although [14] considered the pre-tensioned confining pressure into the expression by adding the pre-tensioned confining pressure into $f_{l}$, the expression overestimated the peak strain up to $70 \%$. This indicates that the sum of pre-tensioned confining pressure to $f_{l}$ is not suitable to predict the peak strain of confined concrete.

\subsection{Effect on Post-Peak Region}

Pre-tensioned level changes the post-peak stress-strain curve of confined concrete. This was observed in [7, 12, 14]. It was found that the higher the pre-tensioned level, the faster the confined concrete loses its strength. This can be seen in the post-peak region as shown in Fig. 2. This can be explained by the yielding of the confining material used in the research. As the material yields, the confining pressure stops increasing and the effectiveness of the confinement will become lower. The higher the pre-tensioned level, the faster the confining material yields, hence the faster the confined concrete loses its strength. In confined concrete without pre-tensioned force, it was observed that strain hardening occurs in higher confinement ratio and strain softening occurs in lower confinement ratio as shown in Fig. 2 [7]. This suggests that the post-peak stress-strain behaviour of confined concrete is affected by both confining pressure and pre-tensioned level.

There are also several studies indicated that pre-tensioned level affects the ultimate strain of confined concrete [7, 13, 14]. In those research, high pre-tensioned level confined concrete has lower ultimate strain compared to confined concrete without pretensioned force. This is because the confining materials were more stressed and it ruptures earlier as illustrated in Fig. 4. However, there has not been any research conducted to verify if the rupture strain of pre-tensioned confining material in confined concrete is similar to its rupture strain in tensile test.

\section{Conclusion}

Applying pre-tensioned force in confined concrete is a good approach to maximize the effectiveness of confinement. However, previous studies indicated that overly pre-tensioned the confinement would turn out to be ineffective. Investigation on the reduction in strain capacity due to pre-tensioned effect has to be conducted and to be included into future research. This review suggests that there exists an optimum pre-tensioned level for each confining material in which the confining material can be fully utilised.

\section{Acknowledgement}

This work was funded by the Fundamental Research Grant Scheme (FRGS) from the Ministry of Higher Education, Malaysia
(R.J130000.7822.4F826). The authors also would like to thank the Universiti Teknologi Malaysia (UTM) for all sorts of supports.

\section{References}

[1] T. Ozbakkaloglu, J. C. Lim, and T. Vincent, "FRP-confined concrete in circular sections: Review and assessment of stressstrain models," Engineering Structures, vol. 49, pp. 1068-1088, 2013/04/01/ 2013.

[2] L. Lam and J. Teng, "Ultimate condition of fiber reinforced polymer-confined concrete," Journal of Composites for Construction, vol. 8, pp. 539-548, 2004.

[3] T. Ozbakkaloglu and D. J. Oehlers, "Manufacture and testing of a novel FRP tube confinement system," Engineering Structures, vol. 30, pp. 2448-2459, 2008.

[4] S. Pessiki, K. A. Harries, J. T. Kestner, R. Sause, and J. M. Ricles, "Axial behavior of reinforced concrete columns confined with FRP jackets," Journal of Composites for Construction, vol. 5, pp. 237 245, 2001.

[5] Y. Xiao and H. Wu, "Compressive behavior of concrete confined by carbon fiber composite jackets," Journal of materials in civil engineering, vol. 12, pp. 139-146, 2000.

[6] L. Lam and J. Teng, "Design-oriented stress-strain model for FRPconfined concrete in rectangular columns," Journal of Reinforced Plastics and Composites, vol. 22, pp. 1149-1186, 2003.

[7] H. Moghaddam, M. Samadi, K. Pilakoutas, and S. Mohebbi, "Axial compressive behavior of concrete actively confined by metal strips; part A: experimental study," Materials and Structures, vol. 43, pp. 1369-1381, December 012010.

[8] H. Moghaddam, M. Samadi, and K. Pilakoutas, "Compressive behavior of concrete actively confined by metal strips, part B: analysis," Materials and structures, vol. 43, pp. 1383-1396, 2010.

[9] M. Shin and B. Andrawes, "Experimental investigation of actively confined concrete using shape memory alloys," Engineering Structures, vol. 32, pp. 656-664, 2010/03/01/2010.

[10] A. Z. Awang, "Stress-strain behaviour of high-strength concrete with lateral pre-tensioning confinement," Universiti Teknologi Malaysia, 2013.

[11] Q. Chen, M. Shin, and B. Andrawes, "Experimental study of noncircular concrete elements actively confined with shape memory alloy wires," Construction and Building Materials, vol. 61, pp. 303311, 2014/06/30/ 2014

[12] H.-P. Lee, A. Z. Awang, and W. Omar, "Experimental Investigation on SSTT Confined Concrete with Low Lateral Pre-tensioning Stresses," 2014.

[13] Y. Wei and Y.-F. Wu, "Compression behavior of concrete columns confined by high strength steel wire," Construction and Building Materials, vol. 54, pp. 443-453, 2014/03/15/ 2014.

[14] N. Holmes, D. Niall, and C. O'Shea, "Active confinement of weakened concrete columns," Materials and Structures, vol. 48, pp. 2759-2777, 2015.

[15] T. Ozbakkaloglu and J. C. Lim, "Unified Stress-Strain Model for FRP and Actively Confined Normal-Strength and High-Strength Concrete," Journal of Composites for Construction, vol. 19, p. 4014072, 2015.

[16] H. Tran, X. Balandraud, and J. F. Destrebecq, "Improvement of the mechanical performances of concrete cylinders confined actively or passively by means of SMA wires," Archives of Civil and Mechanical Engineering, vol. 15, pp. 292-299, 2015/01/01/2015.

[17] P. Li and Y.-F. Wu, "Stress-strain behavior of actively and passively confined concrete under cyclic axial load," Composite Structures, vol. 149, pp. 369-384, 2016/08/01/ 2016.

[18] M. Nematzadeh, S. Fazli, M. Naghipour, and J. Jalali, "Experimental study on modulus of elasticity of steel tube-confined concrete stub columns with active and passive confinement," Engineering Structures, vol. 130, pp. 142-153, 2017/01/01/2017.

[19] A. Awang, W. Omar, L. Hoong-Pin, and C. Ma, "Behaviour of Externally-Confined High-Strength Concrete Column Under Uniaxial Compression Load," in The 8th Asia Pacific Structural Engineering \& Construction Conference (APSEC 2012) and The 1st International Conference of Civil Engineering Research (ICCER 2012), 2nd-2012a, Surabaya, Indonesia, ISBN, 2012, pp. 978-983.

[20] A. Z. Awang, W. Omar, C. Ma, and M. Liang, "Design of short SSTT-confined circular HSC columns," International Journal of Research in Engineering and Technology, vol. 2, pp. 331-336, 2013

[21] H.-P. Lee, A. Z. Awang, and W. Omar, "Steel strap confined high strength concrete under uniaxial cyclic compression," Construction and Building Materials, vol. 72, pp. 48-55, 2014/12/15/ 2014. 
[22] C. K. Ma, A. Z. Awang, R. Garcia, W. Omar, and K. Pilakoutas, "Behaviour of over- reinforced high- strength concrete beams confined with post- tensioned steel straps-an experimental investigation," Structural Concrete, vol. 17, pp. 768-777, 2016.

[23] C. K. Ma, A. Z. Awang, R. Garcia, W. Omar, K. Pilakoutas, and M. Azimi, "Nominal curvature design of circular HSC columns confined with post-tensioned steel straps," in Structures, 2016, pp. $25-32$

[24] C. K. Ma, A. Z. Awang, W. Omar, M. Liang, S. W. Jaw, and M Azimi, "Flexural capacity enhancement of rectangular high- strength concrete columns confined with post- tensioned steel straps: experimental investigation and analytical modelling," Structural concrete, vol. 17, pp. 668-676, 2016.

[25] C.-K. Ma, A. Z. Awang, W. Omar, and L. Maybelle, "Experimental tests on SSTT-confined HSC columns," Magazine of Concrete Research, vol. 66, pp. 1084-1094, 2014.

[26] C. X. Dong, A. K. H. Kwan, and J. C. M. Ho, "A constitutive model for predicting the lateral strain of confined concrete," Engineering Structures, vol. 91, pp. 155-166, 2015/05/15/2015.

[27] F. E. Richart, A. Brandtzaeg, and R. L. Brown, "A study of the failure of concrete under combined compressive stresses," University of Illinois at Urbana Champaign, College of Engineering. Engineering Experiment Station.1928. 